\title{
Introduction - Diversity in Applied Linguistics: Opportunities, Challenges and Questions
}

\author{
James Simpson, University of Leeds \\ Lou Harvey, University of Leeds \\ Clare Wright, University of Leeds
}

This volume provides wide-ranging insights into the current state of applied linguistics. We focus on the existence of and need for diversity in this growing discipline, celebrating half a century since the first annual meeting of the British Association for Applied Linguistics in 1967. Chapters are drawn and developed from the 50th anniversary conference held at the University of Leeds in the summer of 2017 and hosted by the Centre for Language Education Research. Included within these pages are the texts from the three plenary lectures (Widdowson; Woll; Daoud); discussions from the two invited colloquia (Fitzpatrick et al.; Bradley and Harvey); and nine chapters selected through peer review, representing the very best of the $250+$ papers presented at the Leeds conference. Together, this work offers a panoramic view of research in - and commentary upon - applied linguistics five decades or more since the field was established.

How to cite this book chapter:

Simpson, J., Harvey, L. and Wright, C. 2019. Introduction - Diversity in Applied Linguistics: Opportunities, Challenges and Questions. In: Wright, C., Harvey, L. and Simpson, J. (eds.) Voices and Practices in Applied Linguistics: Diversifying a Discipline, pp. 1-9. York: White Rose University Press. DOI: https://doi.org/10.22599/BAAL1.a. Licence: CC BY-NC 4.0 


\section{To mediate relevantly}

Such an anniversary invites reflection, stock-taking and speculation on what is to come. The warrant for examining the field of applied linguistics is strong, professing - as it does - to connect knowledge about language to decisionmaking in the real world. Both 'knowledge about language' and 'the real world' are in flux. New practices and understandings of communication are throwing into question the centrality (if not the importance) of language in contemporary life. And the environments within which communication takes place global and local, physical and social - are experiencing rapid change as never before. The work collected here affords us a space to ask about the principles and purposes of applied linguistics and to consider its direction of travel.

The most widely cited definition of applied linguistics is from Chris Brumfit: the theoretical and empirical investigation of real-world problems in which language is a central issue' (1995: 27). The motivation for applied linguistics therefore lies not with an interest in autonomous or idealised language: applied linguistics is concerned with contexts. Moreover, the interest in 'real-world problems' suggests that this concern goes beyond mere descriptions of language in use. 'Investigation' suggests that a praxis orientation is central, explicitly or implicitly, in much work in applied linguistics, and this is evident in the chapters in this volume. That is to say, reflection (or, as Paolo Freire (1970) would have it, the development of a critical consciousness) and action combine in much applied linguistics study. Reflection alone is clearly not enough. 'One is tempted to wonder,' says Martin Bygate (2005: 570), 'what is so special about studying language within real-world problems if the only purpose is to use it as a stimulus for academic reflection.' A praxis orientation to the field points to the centrality not only of reflection (upon how language is implicated in realworld decision-making) but also action (mediation with practice to inform such decision-making). This aligns well with what applied linguists - certainly the authors of chapters in this volume - seek to do.

A praxis orientation is evident in the areas of applied linguistics which informed its origins. These lie in the mid-20th-century effort to give an academic underpinning to the study of language teaching and learning, a focus reflected in the aims of BAAL at its instigation. For many still today, applied linguistics is most closely associated with the problems and puzzles surrounding language pedagogy, learning and acquisition, which remains the most active area of applied linguistic enquiry. But - following Brumfit's definition - it can hardly be the only one. Practically everything in life poses a problem in which language is central: 'It is hard to think of any "real-world" problems,' comments Greg Myers (2005: 527), 'that do not have a crucial component of language use,' for language is a central issue in most human endeavour. So the role of applied linguists is to make the insights from a broad range of areas of language study relevant to decision-making across an equally broad spread of domains of practice. This volume alone gives a sense of the scope of the field. We touch on sign language and deaf studies, English language curriculum development, primary 
language teacher education, the study of science in higher education, corpus linguistics and academic discourse. Beyond language education - and demonstrating a very healthy range - topics stretch from communicative practices in theatre-making to effective medical interaction to debates around standard language use and multilingualism. Geographically we visit - among other places - suburban London, West Yorkshire and Manchester, and also South Africa, Sri Lanka and Malawi.

If the principle of applied linguistics, and perhaps its defining feature, is praxis, then the purpose is to mediate theory and practice and, moreover, to mediate relevantly. Anticipating arguments aired in Chapter 2, the challenges faced by applied linguists in this respect relate to how to engage with new audiences in new ways, how to relate to policymakers, how to influence debate, and how to ensure that our understandings gain purchase in the public sphere. Organisations such as BAAL can and should support this purpose. Yet, with its disparate theoretical foundations and its multiplicity of concerns, does applied linguistics even have the potential to speak with a common voice?

\section{Coherence and fragmentation}

The theme of the 2017 annual meeting - Diversity in Applied Linguistics: Opportunities, Challenges and Questions - was chosen partly because the organisers wished to echo a previous conference theme, Unity and Diversity in Language Use (at the University of Reading in 2001). The aim of that conference, and of the ensuing edited collection, was to promote and provoke critical reflection on tensions within the discipline between stability and change, consensus and controversy, similarity and variation (Spelman Miller \& Thompson 2002). Since then, supposed unity has come into question still further, with some commentators bemoaning the lack of coherence, and in fact the fragmentation, of our field. In 2015 Guy Cook, a former BAAL chair and also former editor of Applied Linguistics, wrote in that journal of 'Birds out of Dinosaurs: The Death and Life of Applied Linguistics.' In self-confessed grouchy temper, he questioned whether in fact applied linguistics exists any longer, beyond the name of an association or a convenient title for an academic course or journal. The abstract of his paper read, in its entirety, 'This article reflects on the fragmentation and conceptual incoherence of contemporary applied linguistics' (2015: 425).

Drawing upon the evidence within chapters in this volume, we would argue for a more positive stance. The introduction to the Routledge Handbook of Applied Linguistics (Simpson 2011) suggests that, 'though this is an applied field and an interdisciplinary one, it is not fragmented. The distinctive identity of contemporary applied linguistics can be characterized both in conceptual terms and in terms of its scope and coverage' (2011: 1). The claim was made there that unity lies in the common focus on 'real-world problems.' We would retain this claim. Nonetheless, we admit to the challenge presented by the reach 
of a discipline which notices ever more problems to engage with, and problems themselves which become ever more complex and wide-ranging.

We resist examining tea leaves or casting runes. In a world of change, predicting the future of a field that is located at the nexus of psychological, cognitive, communicative, educational, social, cultural and political life is unwise to say the least. Change itself is certain, however, and applied linguistics will travel alongside such change. Human cognition will become further distributed and extended as mobile and online technology merges into the background of existence. In sociopolitical life, and despite the best efforts of those who would strengthen borders and build walls, human mobility will continue to be the dominant paradigm. Communication itself, in social, education and work life, will continue to experience the seismic dislocation of written language from its position of primacy. The job of applied linguists will continue to be to describe, to understand and to shape these and many other future world directions.

Some applied linguists, when in reflective mood, establish their thoughts on a foundation of words from the poets. In his chapter in this volume, Henry Widdowson invokes T.S. Eliot ('Do not let me hear of the wisdom of old men'). In his 2015 paper, Cook cites Pushkin's Eugene Onegin: 'What shameful cunning to be cheerful / With someone who is halfway dead, / To prop up pillows by his head, / To bring him medicine, looking tearful, / To sigh-while inwardly you think: / When will the devil let him sink.' We might respond by quoting Forster in Howards End: 'Only connect the prose and the passion, and both will be exalted, and human love will be seen at its height.' Only connect the connections are there to be made, and are being made: half a century since the first BAAL annual meeting, the papers in this volume demonstrate quite clearly that field is thriving, not standing on the sidelines but engaging with a fluid, mutable, ever-changing and ever-fascinating world.

\section{Overview of chapters}

So to this volume, which is arranged in three sections.

Section A - Applied Linguistics: Looking Back, Looking Forward comprises chapters deriving from - in turn - an invited colloquium, two plenary lectures and a paper presentation from key figures in applied linguistics, taking a discursive, and sometimes personal, take on how they have seen the field develop. The book opens with a composite piece, co-written by six former chairs of BAAL, drawing upon an invited colloquium - a round-table discussion at the 2017 conference. The chapter begins with a framing introduction by Tess Fitzpatrick, and then four former chairs of BAAL (Greg Myers, Ros Mitchell, Mike Baynham and Susan Hunston) in turn present their perspectives on how the field has 'engaged with' policy and practice. In characteristic form, Guy Cook, the discussant at the round-table event, protests at the lack of responsiveness of academics, making the point that we need to engage not only with each other but with the outside world too. 
In the second chapter, Henry Widdowson presents his plenary lecture, in which he develops themes from his earlier work on disciplinarity in applied linguistics, that is, what applied linguistics is and should be. By invoking disciplinarity, Widdowson supposes of course that one thing applied linguistics should not be is a discipline, a field or branch of knowledge, and de facto coherent. His insightful reflections drawn from a lifetime of shaping the field delve carefully into the sometimes thorny issue of how applied linguistics has engaged with the discipline of linguistics and provide clear insights into the ways in which this engagement can continue usefully to inform the practical issues of language use and education which are among the key concerns of applied linguistics.

Next comes a contribution from the second plenary speaker, Bencie Woll, diversifying the field of applied linguistics to consider the position of sign language and Deaf Studies. Bencie's work as a pioneer of deaf language studies has been invaluable in forefronting the importance of applying linguistic paradigms to deaf language studies, and her chapter addresses the current state of deaf language studies, including handling sociopolitical challenges, bilingual contexts and technological opportunities.

In the final chapter in the section, the battleground between positivist and interpretivist paradigms is revisited afresh by Jean-Marc Dewaele, whose entertaining, and at times provocative, chapter considers conceptual disagreement within the field, as it relates to SLA research. Dewaele cautions against throwing the baby out with the quantitative bathwater, arguing that quantitative research has value for the discovery of general trends and for pedagogical development. He makes a claim for the necessity of ontological, epistemological and methodological diversity in the field and calls for more mixed-method studies which can capture the complex interactions of variables among both individuals and groups.

Section B - Applied Linguistics and 'Real-World' Problems begins with a discussion of themes from the second invited colloquium of the conference, on Creative Inquiry in Applied Linguistics. Bradley, Harvey and colleagues posed the questions: What do we understand by creative inquiry? What are its affordances for applied linguistics research? The colloquium was an early move in the establishment of a new research network under the auspices of AILA, the International Association of Applied Linguistics, and the chapter describes several projects from a range of contexts to examine some of the different ways in which applied linguists have worked with the creative arts. It points to a growing interest in the transdisciplinary study of language and arts practice, which Bradley and Harvey suggest is indicative of a creative 'turn' in applied linguistics.

The arts theme is maintained by Kelli Zezulka, reporting her linguistic ethnographic study of language use in theatre lighting design. Understandings gained here about the collaborative talk around arts practice highlight the complex relationships between the different creative practitioners involved in theatre lighting design and the intangible material of light. Zezulka's chapter explores how language operates within the complex power dynamics and hierarchies 
arising in creative and technical settings and shows how the study of communication in these settings can enable a deeper understanding of creative practice and materiality.

Shivonne M. Gates and Christian Ilbury bring a sociolinguistic perspective to ongoing debates on standard language ideologies, discussing data from the talk of young people in London in relation to an educational agenda which sees the use of vernacular language as hindering preparation for the workplace. Drawing on data from two ethnographic studies in east London, they examine the relationship between dialect diversity, standard language ideology and education and articulate the ways in which speakers of non-standard varieties are constrained and challenged through the institutionalisation of standard language ideologies and the internalisation of their effects.

Rachel Chimbwete-Phiri and Malcolm N. MacDonald take us to Malawi and their study of communication in HIV/AIDS medical interactions. They examine how health professionals use strategies which reproduce existing power asymmetries through a regulatory discourse which closes down potential space for the women's own experience and knowledge. Chimbwete-Phiri and MacDonald call for health professionals to attend to the discoursal features of their talk in order to develop health education pedagogies in which women are empowered to engage with their own individual and collective knowledge and which ultimately support more effective HIV/AIDS treatment.

Finally in the section, Dilini Chamali Walisundara interrogates assumptions about language dominance in language policy and practice in heavily multilingual Sri Lanka and how these relate to the discursive construction of culture. The chapter presents research which explored Sri Lankan teachers' awareness of the different minority language groups in the country and their perceptions of linguistic diversity in their classrooms. Walisundara's findings highlight the tensions between teachers' awareness of diversity and its importance and their obligation to teach a national curriculum rooted in English and Sinhalese, articulating implications for the dis/empowerment of speakers of diverse languages.

In Section C - Applied Linguistics and Language Education, we return to language education, the original referent of the field of applied linguistics, but with expanded contextual and methodological lenses taking in multilingual pedagogy, corpus linguistics, modern language teacher training and academic literacies. In the first chapter, based on his 2017 Pit Corder Lecture, Mohamed Daoud takes us to post-revolution Tunisia and Arabic/French-speaking north Africa. Here English language has been taught for decades and yet, though in high demand and valued in all domains, competence remains low. He calls for applied linguists to examine their assumptions about language education and policy and for English teachers particularly to be flexible in their views and practices, playing as they do a key role in managing the tension between developing learner autonomy and working towards curriculum success and sustainability. 
Primary teacher education in the UK is the context for Huw Bell and Stephanie Ainsworth, who examine teachers' responses to a grammar training programme designed to enable them to meet new syllabus requirements. Their insights into teachers' developing attitudes, beliefs and knowledge about grammar teaching show how training can enhance teachers' confidence and better equip them for teaching grammar in increasingly diverse ways. Bell and Ainsworth point to the importance of bringing applied linguistics research back into L1-based classrooms, supporting teachers to better balance structured input and spontaneous discussion, both for pedagogy and for the success of grammar instruction training.

Margaret Probyn's chapter examines classroom linguistic ecologies in linguistically diverse South Africa. Using data from a case study of township and rural schools, Probyn investigates the language used to learn science in a context where teachers' and students' home language is isiXhosa but teaching and assessment take place in English. Her findings on the complex relationship between classroom language and opportunities for science learning have implications for both student and teacher education and for addressing diverse multilingual learners' underperformance in science.

In their study of corpus resources as a tool for improving English collocational competence among Vietnamese university students, Dung Cao and Alice Deignan assessed the benefits of the Oxford Collocation Dictionary of English for their learners' writing through awareness of real-time collocation usage. They found considerable variation in the extent to which the OCDE was perceived to be helpful, concluding that corpus resources have a role to play as a supportive tool in raising learners' awareness of and confidence in using collocations and thus have implications for future learning across diverse educational contexts.

The book closes with a chapter by Rosmawati (the 2017 Christopher Brumfit Award winner for best $\mathrm{PhD}$ thesis), which reports on a study of learners of academic English in Australia. The study built a corpus of academic essays to track participants' development of complex syntax in their writing over the course of a year, drawing on complex dynamic systems theory to examine distinctiveness and diversity both within and across participants' profiles. Rosmawati's findings have clear implications both for understanding of English learners' academic writing and for the design and development of diverse academic English teaching materials, while highlighting the importance for applied linguistics of seeking to diversify such insights for classroom research beyond current dominantly English-speaking contexts.

\section{Looking forward: The next 50 years of applied linguistics}

We have asked whether applied linguistics has the potential to speak with a common voice and have taken the position that the connections are there to 
be made, even in our world of fluidity, mobility and rapid change. Yet we are aware that a common voice comprises multiple voices and that inevitably, in a bounded volume such as this, some voices will (still) be absent. The volume comprises contributions from the 50th BAAL conference, and insofar as this conference is accessible only to those with the material means to attend, and the cultural capital and communicative repertoires to present their knowledgemaking in standard, acceptable ways, the gaps and absences in the volume speak alongside chapters themselves in articulating a view of the field. We are conscious that the global South, and Southern theories, are under-represented in comparison with the global North and conscious too of the ontological role of volumes such as this in reinforcing this inequality. We are also conscious that the volume is published in English, despite the plurilingual nature of the field, and in this sense it reinforces the English-monolingual ideology in global academia. There are some widely adopted language teaching methodologies which are not addressed (e.g., CLIL, SIOP) and little engagement with the future of modern languages education beyond English, for example the current state of foreign language teaching in Anglophone contexts. Nor does the volume engage with the major political events shaping the context of its production most obviously Brexit, ongoing debates around national borders and mobility and the rise of anti-immigration sentiment and exclusionary right-wing ideologies.

These are major questions and concerns for the field to continue to engage with moving forward. And yet, in showcasing the diversity of the field while recognising that that diversity is necessarily limited, we do not want to fetishise diversity for its own sake: as long as an academic product - a conference, a research project, an edited volume - is bounded, as it must necessarily be, it can always be more diverse. Perhaps the ultimate challenge for applied linguistics as a discipline lies not in expanding its diversity but rather in finding ways to negotiate the tension between, on the one hand, the necessity to acknowledge diversity and, on the other, the recognition of its potential to reinforce difference and otherness in reifying and essentialising ways. We look forward to being part of applied linguistics' engagement with these concerns over the coming years as we collectively forge the future of the discipline.

\section{References}

Brumfit, C. 1995 Teacher professionalism and research. In Cook, G. and Seidlhofer, B. Principle and Practice in Applied Linguistics. Oxford: Oxford University Press. pp. 27-41.

Bygate, M. 2005 Applied linguistics: A pragmatic discipline, a generic discipline? Applied Linguistics, 26(4): 568-581.

Cook, G. 2015 Birds out of dinosaurs: The death and life of applied linguistics. Applied Linguistics, 36(4): 425-433. 
Freire, P. 1970 Pedagogy of the oppressed (trans. M Ramos). Reissued 2005. New York: Continuum.

Myers, G. 2005 Applied linguists and institutions of opinion. Applied Linguistics, 26(4): 527-544.

Simpson, J. (ed.) 2011 The Routledge handbook of applied linguistics. Abingdon, Oxon and New York: Routledge.

Spelman Miller, K. and Thompson, P. (eds) 2002 Unity and diversity in language use. Proceedings of the 34th Annual BAAL Conference. London: Continuum Press. 